\title{
A Model for Calculating Shock Loading and Release Paths for Multicomponent Geologic Media
}

T. R. Butkovich

B. Moran

D. E. Burton

July 1981 
[CRL-53]:8

Distrihution ( atckory $(\mathrm{C}-1)$

\section{A Model for Calculating Shock Loading and Release Paths for Multicomponent Geologic Media}

T. R. Butkovich

B. Moran

D. E. Burton

Manuscript date: July 1981

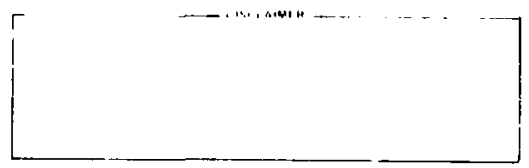

LAW'R.ENCE. LIVERMORE LABORATORY University of California - 'ivermore, California 94550 


\section{CONTENTS}






\title{
A MODEL FOR CALCULATING \\ SHOCK LOADING AND RELEASE PATHS \\ FOR MULTCOMPONENT GEOLOGIC MEDIA
}

\begin{abstract}
A model has been devised to calculate shock Hugoniots and release paths of the Hugoniots for multicomponent rocks containıng silicate, carbonate, and water. Hugoniot equations of state are constructed from relatively $51 \mathrm{mpl} c$ measurements of rock properties including $t$ ilk density, grain density of the ril lcate mmpnent, and weight fractions of water and carbonate. Release pathr of $t$ the comprsite Hugoniot are caiculateo by mixing releare paths of the comment Huaniots according to their weight fractions. Il the shock imparts rufficient enerqy to the component to cause vaporization, a gas rquation of rtati. is used to calculate the release paths. For less energetic r rocke, the rock rmponent will unload like a solıd or liquid, taking into account : hr arrouscible remova? of air-filled porosity.
\end{abstract}

\section{INTRODUITION}

Underground nuclear explosions have been conducted in a Large variety of geological settings. Most commonly, the detonations take place in silicate rocks. Some rocks contain carbonates. Most rocks have associated porosity and are fully or partially satus ated with water.

In modeling the phenomenology of underground nuclear explosions with finite difference codes such as $\operatorname{soc}^{1}$ and TENsOR, ${ }^{2}$ it is necessary to define the pressure, density, and energy states (PVE) that are attained by the surrounding rock over the entire pressure range experienced. This includes both the loading paths and the appropriate PVE unloading paths $f_{i}$ un the Hugoniot. The Hugoniot curve is formed by a locus of shock states in the pressure-volume plane. If the shock adds sufficient energy to the material to cause it to vaporize, a gas equation of state is required to calculate the unloading paths off the Hugoniot for each of the components of the rock present in the vapor state. 
The computation of the equation of state draws on the knowledge of several branches of physics and chemistry. Much of the PVE-state surface is inaccessible to controlled experiments so that input to these regions are obtained from theory. In some regions it is not possible to give rigorous theoretical treatment and, where theories give different results, it is necessary to exercise judgment in selecting the most accurate one. Single shock Hugoniot curves can be obtained by direct measurement but, even here, extrapolations need to be made to extend them into the extremely high-pressure regime inaccessible to experiments.

In an underground nuclear explosion, all of the energy is released in less than a microsecond. At this instant, the energy is concentrated in a small volume of extremely high temperature, high pressure material which generates a strong shock wave that propagates through the surrounding rock, distributing the energy as it decays. Close in, the rock is completely vaporized, and this vaporized rock itself becomes the primary working gas. The gas expands forming a cavity by displacing the surrounding rock. Iit this region, a gas equation of state is used to calculate the adiabatic release paths of $f$ the Hugoniot for each element of the vaporized rock. For the region farther from the explosion center, where not enough energy is available for vaporization, release paths from the Hugonlot are calculated, taking into account the irreversible removal of air-filled porosity.

Using complex theoretical models and associated computer codes, a gas equation of state can be calculated for any specific mixture of chemical compounds. In nature, an almost infinite variety of mixtures of different weight fractions of silicates, carbonates, and water can exist. The process of putting the results of one set of calculations for a given mixture in a form acceptable to our finite difference codes is a long and tedious one and does not lend itself to computer algorithms.

In this paper we describe a model for the construction of pressure-volume loading curves (Hugoniots) through the entire range of pressures that might be experienced in the rock surrounding an underground nuclear explasion $110^{-1}$ to $10^{9} \mathrm{MPa}$ ). The omposite rock can be comprised of any ratio of silicate, carbonate, or water. 
State points above a temperature of $1 \mathrm{eV}\left(1.16 \times 10^{4} \mathrm{~K}\right)$ were calculated for each component using the Lawrence Livermore National Laboratory (LLNL) Ionization Equilibrium Equation of state code (IEEOS). ${ }^{3-7}$ The IEEOs is based on classical theory and can accomodate a mixture of up to 10 elements. In the thermochemical region, where equations governing tlue system are known and some data is available, the TIGER code was used. The TIGER code can randie some aspects of non-ideal gas behavior and more than ore condenseci pharn. As input, TIGER reciuires the following: 1$)$ co-volume: of gas species for the $k_{1} \cdots$ a aroweky-kilson equation of Etate, 2 ; enthalpies of formation of the compound: : al: : ate ontropy at the reference temperatur (29k k), ani 4) specific tonat: at cos:at ant picserure as a function of temperature tor ald species present. The Ifeos codo requires all the iomization poteritals for each element present.

HLGONIOT EQUATIONS OF STATE

The model used to calculate the pressure-volume (p-V) relationships (Hugoniot) for each component: is an extension of the work by Butkovich. ${ }^{9}$ The Rankine-Hugoniot condition is used which relates measurements of snock velocity $u_{s}$ and particle velocity $u_{p}$ through equations derived from the laws of conservation of mass and momentum given in Eq. (J).

$$
\frac{P-P_{0}}{v_{0}}=U_{s} U_{p} \text { and } \quad \frac{v}{v_{0}}=\frac{U_{s}-U_{p}}{U_{s}} \text {. }
$$

Experimentally determined variables $U_{s}$ and $U_{p}$ associated with a single shock are found to be linearly related over large pressure $r$ anges. Using this, 1 inear fits were made to the data where the data existed in the form

$$
u_{s}=a+b u_{p}
$$


and were extrapolated. Butkovich constructed a model which reproduced shock and compressibility data on a large variety of partially to fully water-saturated silicate rocks, using easily measurable rock properties such as bulk density, grain density, and weight fraction of water.

The present work extends the model to include the effect of the carbonate component and thermal heating using the Mie-Grineisen equacion.

The required input parameters are:

$\mathrm{Z}$ = weight fraction of water $\left(\mathrm{H}_{2} \mathrm{O}\right)$,

$c$ = weight fraction of carbonate $\left(\mathrm{CaCO}_{3}\right)$.

$r_{c}=$ bulk density of composite material,

$D_{G S}=$ grain density of silicate component,

$f_{G C}=$ grain density of carbonate component.

${ }^{\prime}{ }_{i}=$ initial air-filled porosity.

Calculated, inferred, or default parameters are:

$\Gamma_{0}=$ Grineisen parameter where $\Gamma_{n}=\frac{\Gamma}{V}(0.5$ is default $)$,

$S=$ weight fraction of silicate $(S=1-z-C)$,

$n_{\mathrm{GC}}=$ grain density of carbonate $\left(2.712 \mathrm{~g} / \mathrm{cm}^{3}\right)$ is default for $\mathrm{CaCO}_{3}$.

The $P-V$ curves for each of the three components are calculated from $l$ inear fits to their $U_{s}$ vs $U_{p}$ data. The coefficients $a$ and $b$ in Eq. (2) that best $f$ it the data are used. Equations (1) and (2) are solved for $V$ in terms of $F$, using the coefficients $a$ and $b$ from Eq. ( 2 ). The resulting equations are

$$
v=\left[\frac{a(b+1)+R(b-1 ;}{b(a+R)}\right] v_{G} \text {, }
$$

where

$$
R=\left(a^{2}+4 b P V_{G}\right)^{1 / 2}
$$

Here $V_{G}$ is the reciprocal of the grain density for a particular component. At atmospheric pressure $(0.1 \mathrm{MPa})$; silicate rocks have a range of grain densities between 2.3 and $2.8 \mathrm{~g} / \mathrm{cm}^{3}$, depending upon their mineral composition. The carbonate $\left(\mathrm{CaCO}_{3}\right)$ grain density is $2.712 \mathrm{~g} / \mathrm{cm}^{3}$ and the water density is $0.998 \mathrm{~g} / \mathrm{cm}^{3}$. 
For the silicate component, empirical fits were obtained for $U_{s}$ vs $U_{p}$ Hugoniot data for grain densities between 2.3 and $2.8 \mathrm{~g} / \mathrm{cm}^{3}$ (see Ref. 9 ).

$$
\begin{gathered}
\left.\begin{array}{c}
a=0.3427 r_{G S}-0.432 \\
b=4.598-1.568 c_{G S}
\end{array}\right\} \quad \text { for } P<P=\rho_{G S}\left(0.0028 P_{G S}+0.112\right) \\
\left.\begin{array}{c}
a=0.235 \\
b=1.60
\end{array}\right\} \quad \text { otherwise. }
\end{gathered}
$$

The raiues of the coeffleients a and $b$ and used in Egs. (3) and (4), give - in Mbars 110 MPa! and $\mathrm{V}$ in $\mathrm{cm}^{3}, \mathrm{~g}$.

A fit to the avallable data for grain density laco, provides

$$
\begin{aligned}
& a=0.380 \\
& b=2.425
\end{aligned}
$$

Frr tif wator component, the $U_{s} \cdots L_{p} r \in$ lationship was obtalned by ittir.u the availatile data. The extrapolated region was fitted to resul:s


$\therefore$ traight line segments with the parameters shown in Table 1 .

The p-Y paints tre calculated by substituting a selected Hugonict Frnesure $P_{H}$ anto Eq. (4), solving tor $R$, and using this value in $\mathrm{Eq}$. (3) to

\begin{tabular}{|c|c|c|c|}
\hline a & b & $\underset{(m / s)}{U_{p}}$ & $\begin{array}{c}\text { pressure range } \\
\text { (MPa) }\end{array}$ \\
\hline 0.176 & 1.65 & $\leq 2.6 \times 10^{4}$ & $<1.5 \times 10^{4}$ \\
\hline 0.320 & $1 . .14$ & $>2.6 \times 10^{4}$ and $<10^{5}$ & $>1.5 \times 10^{4}$ and $<1.5 \times 10^{5}$ \\
\hline 0 & 1.294 & $>10^{5}$ & $>1.5 \times 10^{5}$ \\
\hline
\end{tabular}
nbtain the corresporiding $V$. The result is a curve defining a locus or shock

TABLE 1. Values of coefficients for straight-line segments for water.

\section{Corresponding}


states for a non-porous component. If the component is porous, then the non-porous curve is adjusted using the Mie-Grüneisen equation

$$
P=P_{H}+\Gamma\left(E-E_{H}\right)
$$

where

$$
\frac{r_{0}}{v_{H}}=\Gamma=\text { constant },
$$

where the subscript $H$ refers to the values of the variables on the lion-porous llugoniot. This equation calculites a pressure greater than $\mathrm{P}_{H}$ to compress purnus material from $v_{t}$ to $v_{\text {, where }} v_{t}=v_{G} /(1-\$)$ and wher $v_{\text {: }}$ is the speciela volump of the porous component. The relationship below derived from Eq. $: 6$, is used.

$$
F=\frac{1-\frac{\Gamma}{2}\left(v_{G}-v\right)}{1-\frac{\Gamma}{2}\left(v_{t}-v\right)}
$$

where

$$
\mathbf{P}=\mathrm{FP}_{\mathrm{H}}
$$

Figure 1 shows a typical non-porous loading curve with adjustment for porosity.

When sone initial air-filled porosity, $\Psi_{j}$, is oresent in the composite rock, it is assumed to be the same in the silicate and carbonate components and is removed irreversibly by compaction. The rock is assumed to be elastic to some threshold pressure, $P_{T}$, for the onset of compaction. At pressures greater than $P_{T^{\prime}}$ air-filled porosity is removed exponentially to a pressure, $P_{m}$, at which. all the air-filled porosity is removed. If the pressure is released from $P_{m}$ or above, the release path will be that corresponding to $\psi_{i}=0$. Both $P_{T}$ and $P_{m}$ are dependent on water content or on the initial air-filled porosity, according to the empirically determined relationships ${ }^{9}$ shown in Eqs. (7) and ( 8 )

$$
B_{T}=\frac{1}{\exp \left(C \psi_{1}+D\right)}
$$




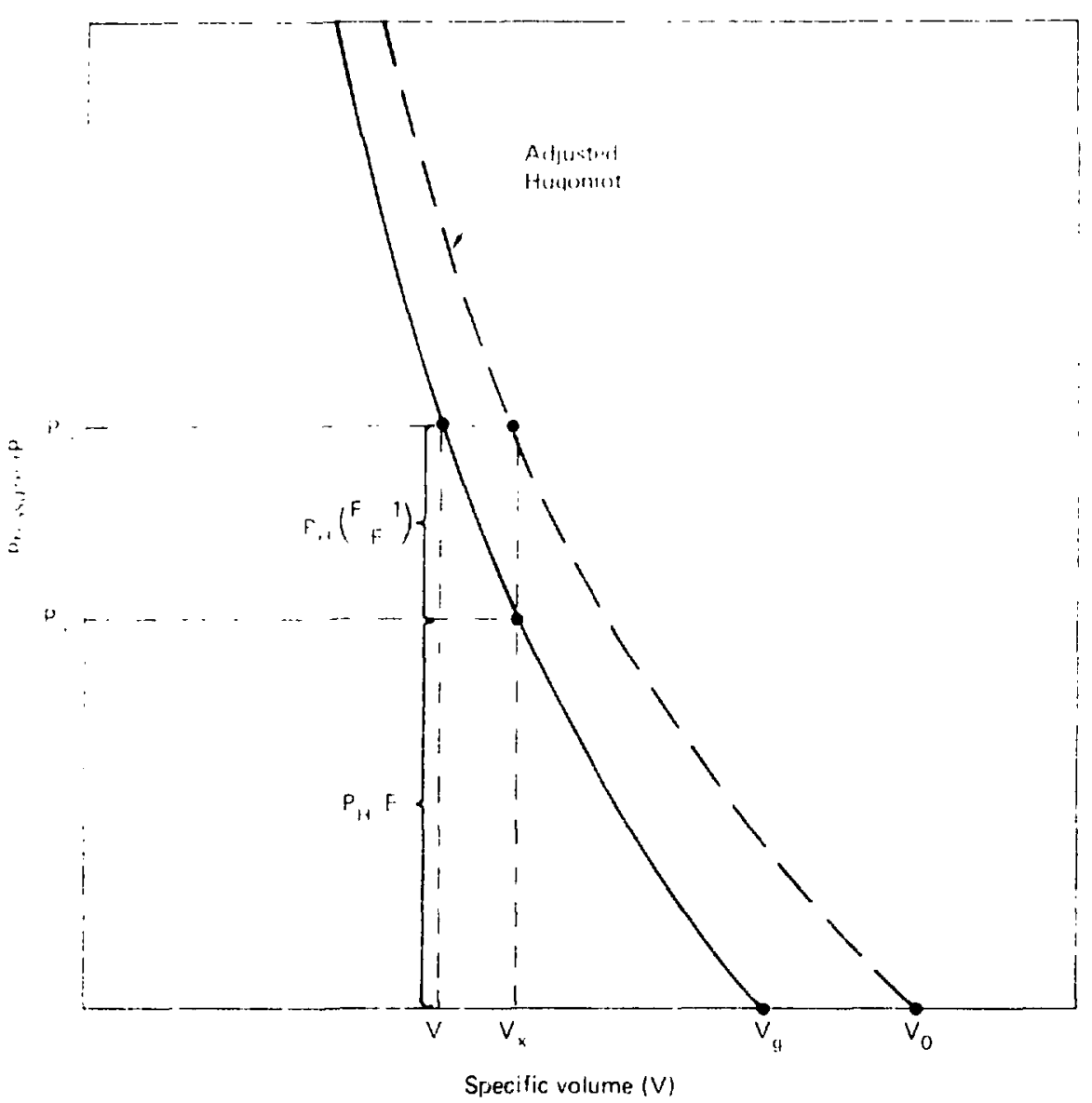

FIG. 1. Typical non-porous lcading curve adjusted for porosity. 
Table 2 gives the values of the parameters, $C$ and $D$, as a function of the weight fraction of water, $z$.

$$
\begin{array}{ll}
P_{m}=6.5 \times 10^{-4} z^{0.944} & \text { for } z>0.01 \\
P_{m}=0.05 & \text { for } z-0.01
\end{array}
$$

The coefficients $\mathrm{glven}$ in Eqs. (i) and (8) are for $\mathrm{P}$ in $\mathrm{Mb}\left(10^{5} \mathrm{MFa}\right.$ ) and $y$ in $\mathrm{cm}^{3} / \mathrm{g}$.

TABIF: 2. Values of parameters $C$ and $D$ as a function of the weight fraction of

\begin{tabular}{|c|c|c|}
\hline Weight fraction of $\mathrm{H}_{2} \mathrm{O}$ & -- & \\
\hline$z$ & $c$ & D \\
\hline $0<z<0.05$ & 6.579 & 6.908 \\
\hline $0.1>2>0.05$ & 4.859 & 8.112 \\
\hline$z>0.1$ & 3.369 & 8.805 \\
\hline
\end{tabular}
water (sec Eq. 7).

SHOCK LOADING AND RELEASE PROCESS

The shock compression process is assumed to occur in the following manner: From an initial state at ambient pressure, $P$ ( 0.1 MPa), temperature, $T(298 \mathrm{~K})$, and density, $\rho_{0}$, an element of multicomponent material undergoes a single shock compression. On shocking material to pressures greater than $P_{m}$, all air-filled porosity present is removed irreversibly. On shocking a material to very high pressures, a large increase in internal energy in the form of mechanical $P \Delta V$ work is added to the shocked material. Depending upon its compressibility, each component will receive a different increment of the added energy. Phase changes can occur in one component at a given shock pressure bu? not in the others.

The "waste heat concept"1l is useful for estimating prak shock pressures where it is necessary for phase changes to occur in the various components being considered. In this concept the total energy acquired is 
divided into available energy and "waste heat," where the "waste heat" is defined to be the net energy per unit mass which remains in the material after it expands adiabatically to its initial pressure.

Partial vaporization of the water component can begin on unloading from a peak shock pressure above about $10^{4} \mathrm{Mpa}^{5}$ A ralue of $28^{n n} \mathrm{cal} / \mathrm{g}$ was derived by G. H. Higgins ${ }^{12}$ as a good estimate for the increase in the internal etorgy required to totally vaporize $\mathrm{SiO}_{2}-\mathrm{H}_{2} \mathrm{O}$ mixtures. ${ }^{13}$ This occurs for shocks with peak pressures above about $1.5 \times 10^{5} \mathrm{MPa}$, depending upon the grain-density compressibility of the silicate rock component.

For the $\mathrm{CaCO}_{3}$ componnt, decomposition will occur with a change of enthalpy of about $400 \mathrm{cal} / \mathrm{g} .14$ For non-forous $\mathrm{CaCO}_{3}$, this wo $1 \mathrm{~d}$ occur upon release from peak shock pressures greater than about $5 \times 10^{4} \mathrm{MPa}$. $T$ :al vaporization of the carbonate component occurs with changes in enthalpy of abrit $4000 \mathrm{cal} / \mathrm{g}$ (Ref. 24); that is, when this amount of energy is available, the $\mathrm{CaO}$ component of the decomposition products $\mathrm{CaCO}_{3} \rightarrow \mathrm{CaO}+\mathrm{CO}_{2}$ is totally vaporized. This would occur for shock pressures above about $2.5 \times 10^{5} \mathrm{MPa}$ for non-porous $\mathrm{CaCO}_{3}$. Any additional energy added to the system, by shock loading to pressures higher than necessary to vaporize any of the components, would appear as superheat in the :apor, increasing the pressure in the gas phase.

Release paths from specified points on the fiugoniots are calculated for each component in the following manner. If the peak slock pressure is at or below "r." the porous rock behaves elastically. If the peak shock pressure is at or above $P_{m}$, all the porosity has been removed irreversibly, and the material unloads along the poro.ity adjusted grain density Hugoniot curve. However, if the peak shock pressure is at or above $\mathrm{P}_{\mathrm{v}}$, the pressure at which the onset of vaporization c- decomposition to a gaseous state sccurs, then the release path is calculated from the gas equation of state.

For $\mathrm{P}_{\mathrm{H}}>\mathrm{P}_{\mathrm{v}}$, the release path from any point on the Jlugoniot $\left(\mathrm{P}_{\mathrm{H}^{\prime}}\right.$, $\mathrm{V}_{\mathrm{H}^{\prime}}$ and $\mathrm{E}_{\mathrm{H}}$ ) is obtained by numerically integrating volume changes $\Delta \mathrm{V}$ and energy changes $\Delta \boldsymbol{E}=\mathrm{P} \Delta \mathrm{V}$. Each succeeding $\mathrm{P}$ is obtained by interpolacion of the gas equation of state.

Figure 2 shows the gas equation of state for $\mathrm{SiO}_{2}$ obtained by merging the IEEOS and TIGER code's calculational resultis and plotted as lines of constant density in the specific eneray-pressure plane. When the results 


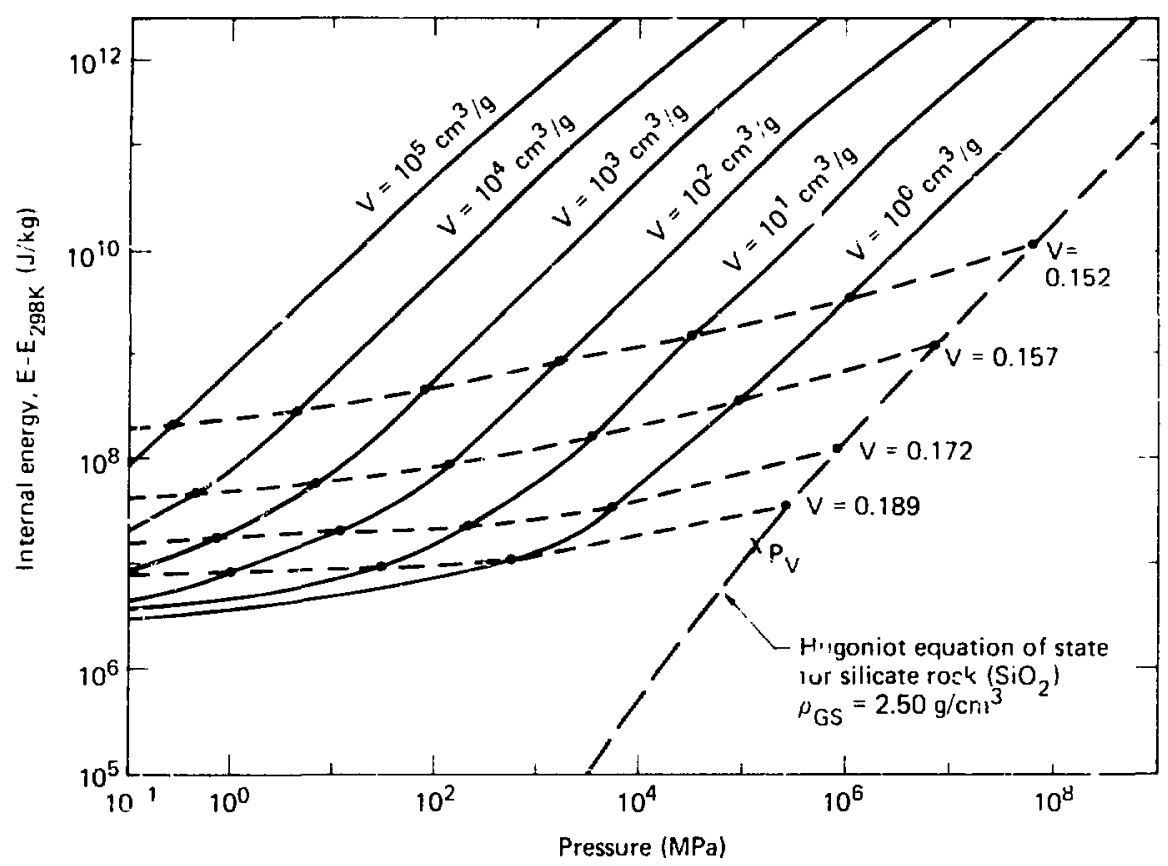

FIG. 2. Gas equation of state for $\mathrm{SiO}_{2}$.

extend into the extremely high energy-dencity region, a radiation correction must be applied to the results. ${ }^{15}$ There is energy and momentum associated with a radiation field, and the esuation of conservation of energy and momentum slould include the contribution of the matter and its radiation field. The radiative contribution is negligible compared to that of matter, except at extremely high temperatures $\left(>1 \mathrm{keV} \approx 10^{7} \mathrm{~K}\right)$ and at lower densities $\left(<1.0 \mathrm{gm} / \mathrm{cm}^{3}\right)$ where the radiative contribution becomes signiricant above $0.1 \mathrm{keV}$. Also shown in Fig. 2 is a typical shock Hugoniot for a grain density (non-porous) silicate rock along with representative release paths.

Figure 3 shows the radiation corrected gas equation of state for $\mathrm{CaCO}_{3}$. The lEEOS and TIGER codes' calculational results are those reported by Pasternak, Lee, and Miller, ${ }^{16}$ and are furnished by them for this work. Figure 4 shows the radiation corrected gas equation of state for $\mathrm{H}_{2} \mathrm{O}$. Both of these ilgures also include their grain density Hugoniot and show representative release paths from different shocked states from their Hugoniots. 


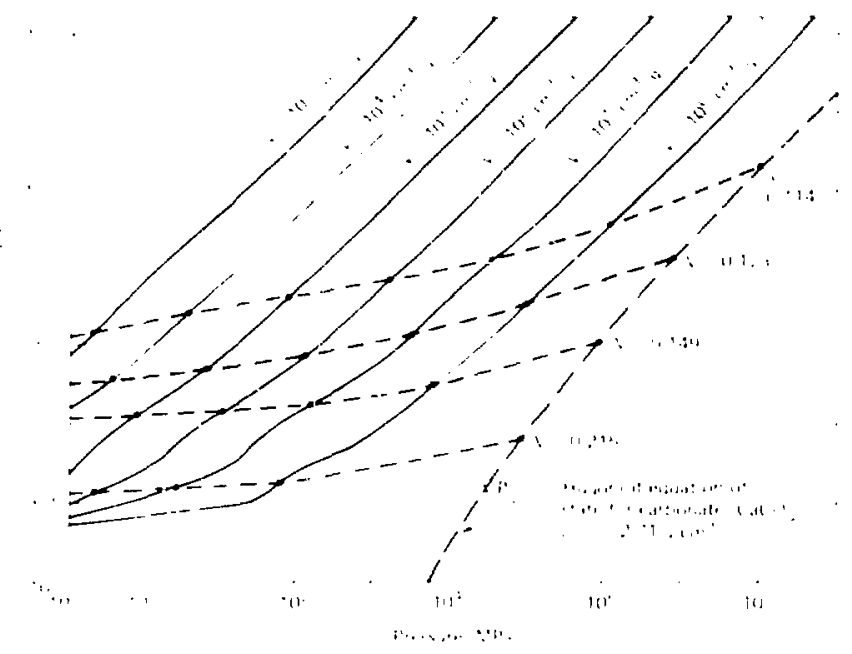

FIG. 3. Radiation corrected gas equation of state for $\mathrm{CaCO}_{3}$.



FIG. 4. Radiation corrected gas equation of state for $\mathrm{H}_{2} \mathrm{O}$. 
Release paths from the selected pressures on respective Hugoniots are calculated for each component. Figures $5 \mathrm{a}$ and $5 \mathrm{~b}$ show Hugoniots and release paths calculated for a pure silicate rock with grain densities 2.3 ano $2.8 \mathrm{~g} / \mathrm{cm}^{3}$, respectively. Figure $5 \mathrm{r}$ is for yrasn density $\mathrm{CaCO}_{3}$, and Fig. $5 \mathrm{~d}$ is for $\mathrm{H}_{2} \mathrm{O}$ (see table 3 for a legend of Figs. 5 to 10 ).

TABLE 3. A leaend for Fijs. 5 to 20 showing calculated release paths of the Huqnonints (the uppermost 1 ine curve is numbered 1 in all figures).

Hugoniot pressure from which the release curves were calculated

\begin{tabular}{|c|c|c|c|}
\hline \multirow[b]{2}{*}{ i,ine No. } & \multicolumn{3}{|c|}{ Pock content } \\
\hline & $\begin{array}{c}\text { silicate }\left(\mathrm{SiO}_{2}\right) \\
\text { (MPa) }\end{array}$ & $\begin{array}{c}\text { Carbonate }\left(\mathrm{CaCO}_{3}\right) \\
\text { (NPa) }\end{array}$ & $\begin{array}{l}\text { Water }\left(\mathrm{H}_{2} \mathrm{O}\right) \\
\text { (MPa) }\end{array}$ \\
\hline 1 & $1.0 \times 10^{9}$ & $1.0 \times 10^{9}$ & $1.0 \times 10^{9}$ \\
\hline$?$ & $3.0 \times 10^{8}$ & $3.0 \times 10^{8}$ & $3.0 \times 10^{8}$ \\
\hline 3 & $1.0 \times 10^{\circ}$ & $1.0 \times 10^{8}$ & $1.0 \times 10^{8}$ \\
\hline 4 & $3.0 \times 10^{\circ}$ & $3.0 \times 10^{7}$ & $3.0 \times 10^{7}$ \\
\hline 5 & $1.0 \times 10^{7}$ & $1.0 \times 10^{7}$ & $1.0 \times 20^{7}$ \\
\hline 6 & $3.0 \times 10^{6}$ & $3.0 \times 10^{5}$ & $3.0 \times 10^{6}$ \\
\hline 7 & $1.0 \times 10^{6}$ & $1.0 \times 10^{6}$ & $i .0 \times 10^{6}$ \\
\hline 8 & $5.0 \times 10^{5}$ & $5.0 \times 10^{5}$ & $5.0 \times 10^{5}$ \\
\hline 9 & $3.0 \times 10^{5}$ & $3.0 \times 10^{5}$ & $3.0 \times 10^{5}$ \\
\hline 10 & $2.0 \times 10^{5}$ & $2.0 \times 10^{5}$ & $2.0 \times 10^{5}$ \\
\hline 11. & $P_{v}$ & $1.0 \times 10^{5}$ & $1.0 \times 10^{5}$ \\
\hline ] 2 & - & $7.0 \times 10^{4}$ & $7.0 \times 10^{4}$ \\
\hline 13 & -- & $5.0 \times 10^{4}$ & $5.0 \times 10^{4}$ \\
\hline 14 & -- & $3.0 \times 10^{4}$ & $3.0 \times 10^{4}$ \\
\hline 15 & -- & -- & $2.0 \times 10^{4}$ \\
\hline 16 & -- & - & $1.0 \times 10^{4}$ \\
\hline
\end{tabular}




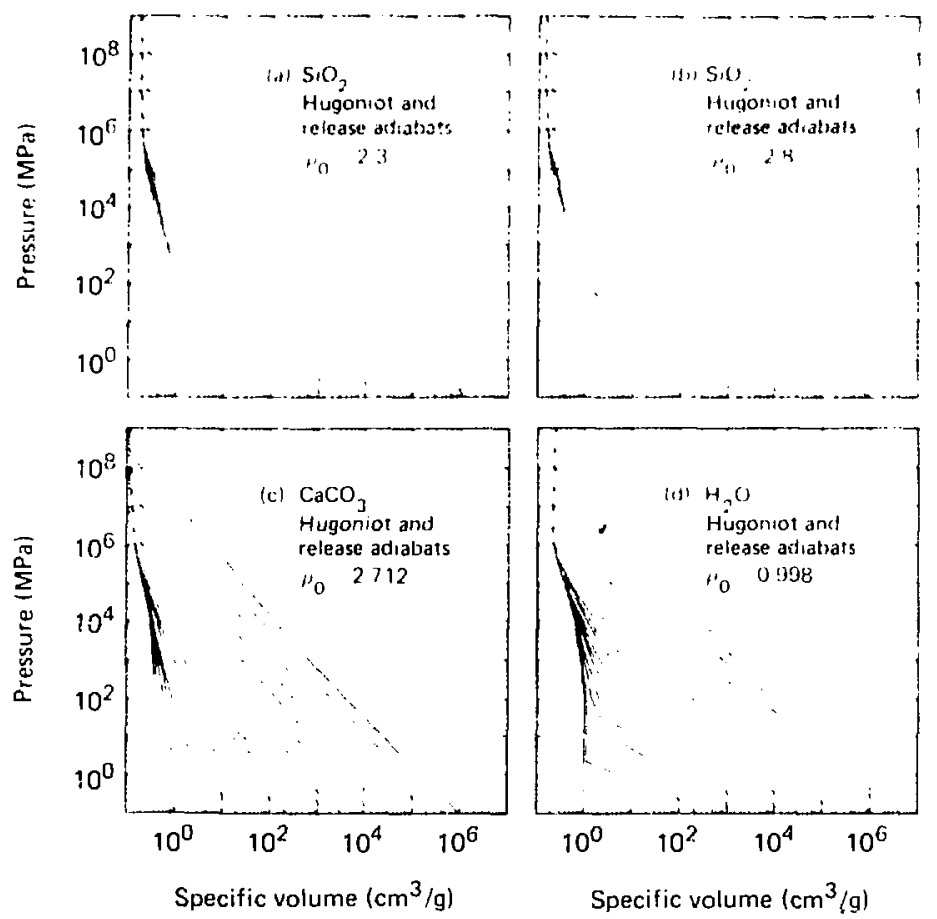

FIG. 5. A comparison of Hugoniots and release paths for pure silicate rock, carbonate, and water. 

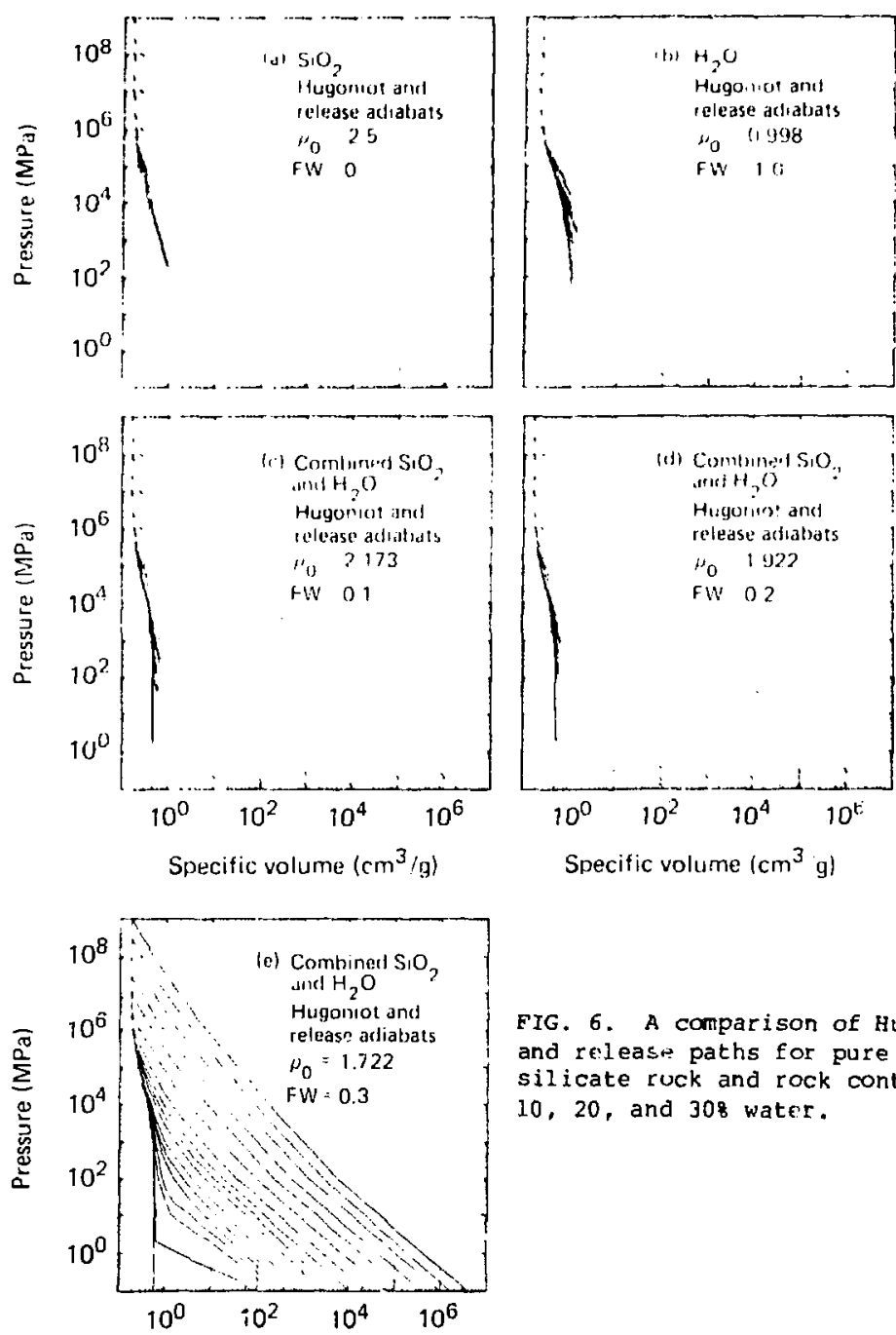

Specific volume $\left(\mathrm{cm}^{3} \mathrm{~g}\right)$

FIG. 6. A comparison of Hugoniots and releaste paths for pure silicate ruck and rock containing 10,20 , and 308 water.

Specific volume $\left(\mathrm{cm}^{3} / \mathrm{g}\right)$ 

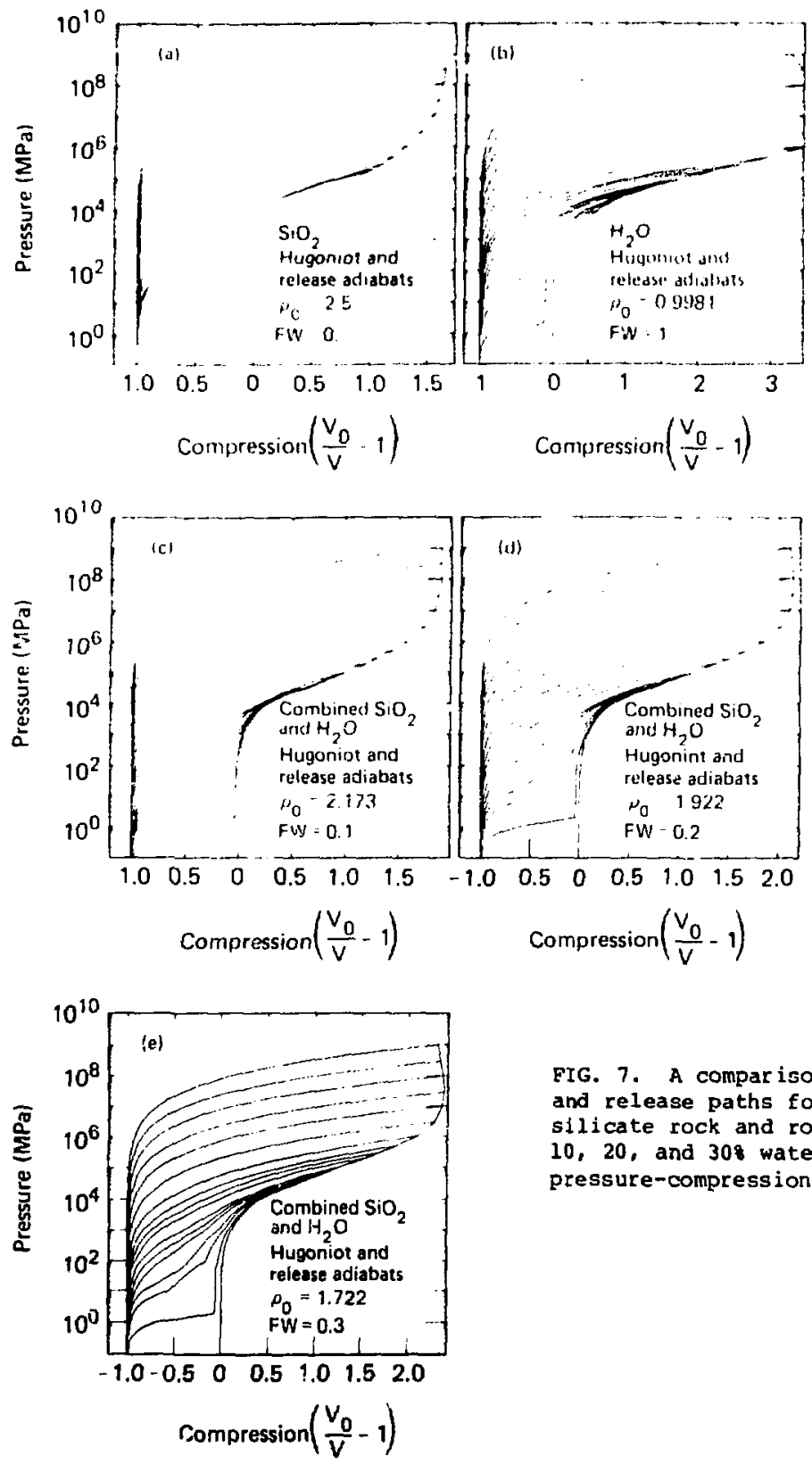

FIG. 7. A comparison of Hugoniots and release paths for pure sllicate rock and rock containing 10,20 , and 308 water in a pressure-compression space. 

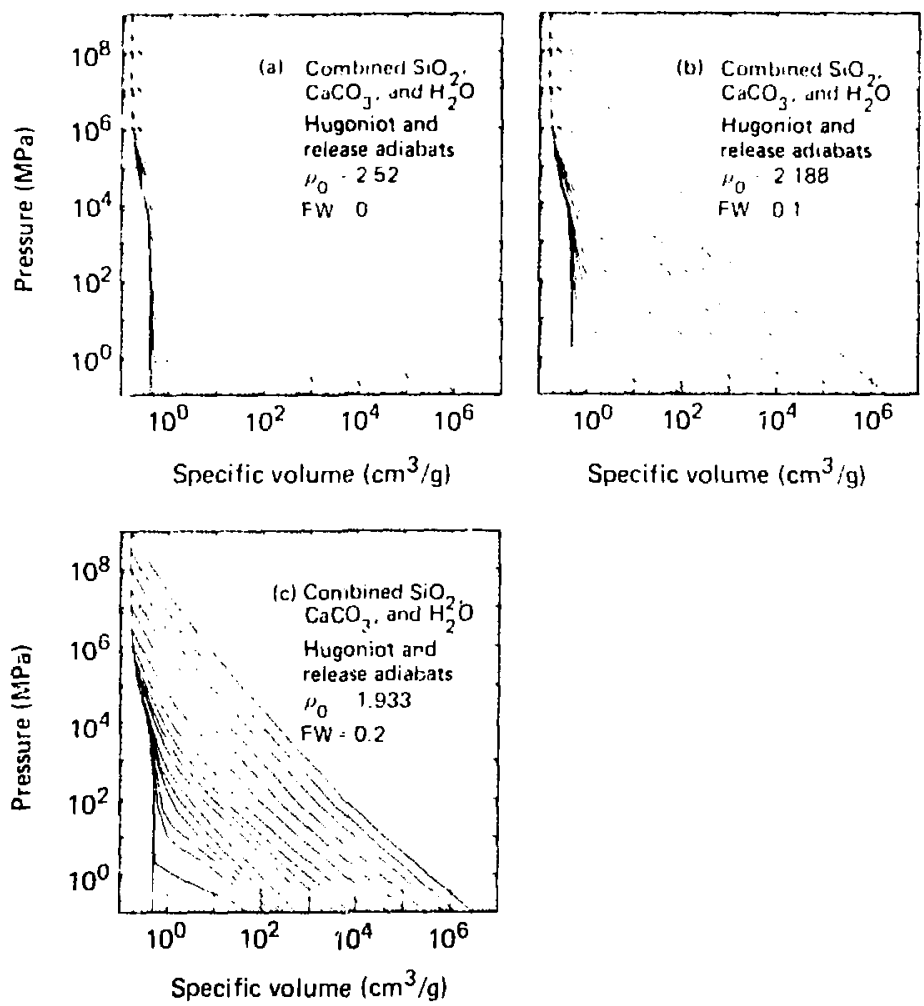

FIG. 8. Tugoniots and release paths for composite rocks. 


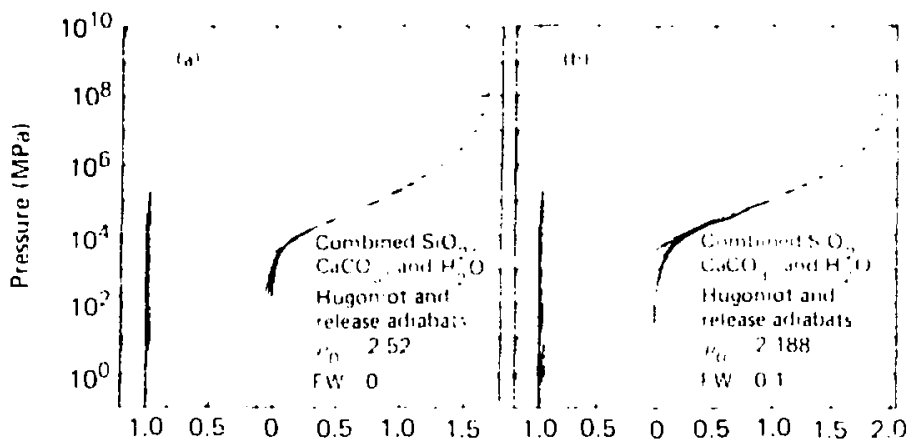

Comprasion $\left(\begin{array}{cc}V_{0} & 1 \\ V & 1\end{array}\right) \quad$ Compression $\left(\begin{array}{cc}V_{0} & 1 \\ V & 1\end{array}\right)$



FIG. 9. Hugoniots and release paths for composite rocks in pressure-compression space. 

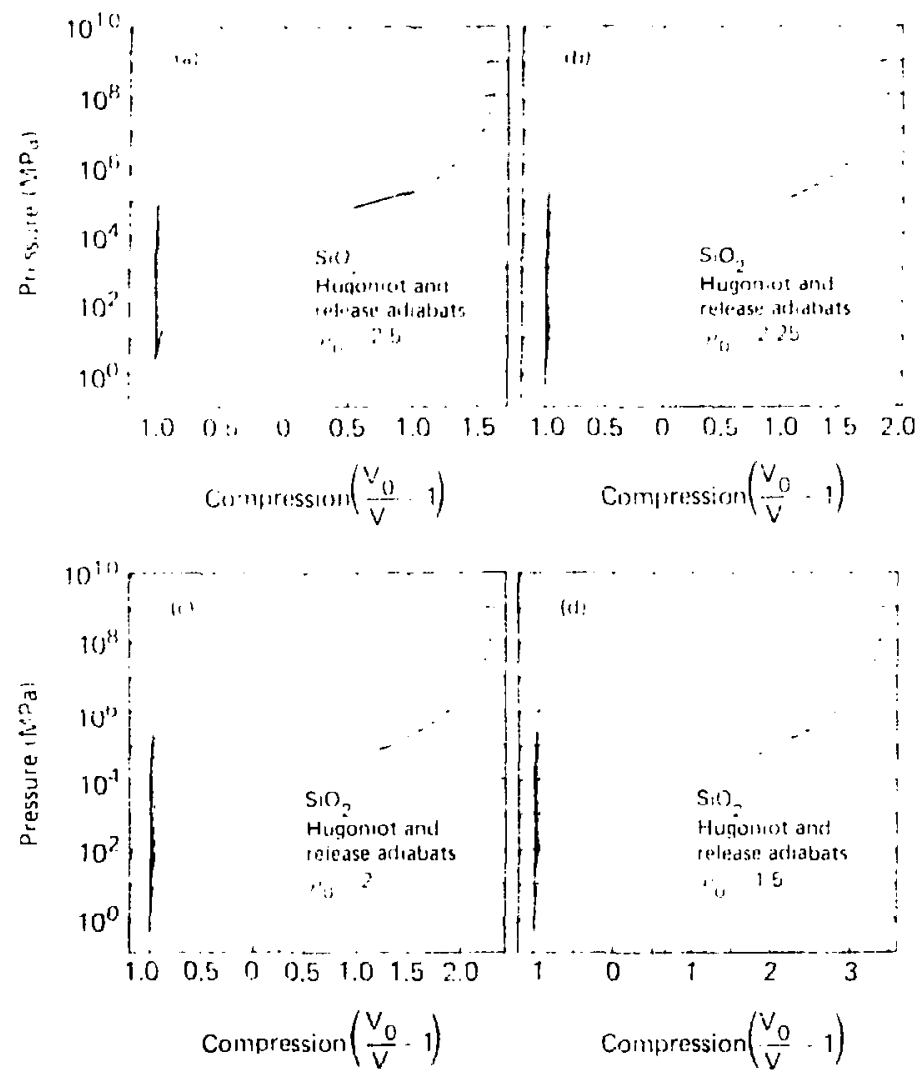

FIG. 10. Release paths for dry, prous silicate rock (SiO). 
Calculating the unloading fram a given shock pressure on the composite Hugoniot for a multicomponent rock is a rather complex procedure. Taken individually, cach component has its own Hugoniot, If sufficient piv work is done on a component, phase changes accur. Solids are transformed into a i iquid or a gas. Componsite release paths then can he made up of various combinatione of solids, liquids, or gases, where one component can expand as a solid and ancther as a gas. When a solid-to-liguid phase chanar occurs, the expansion that follows is not too different than that of the solid phase, with the volume changr being affected primarily by the the:mal heating This: relatively small difference is ignored in the model. Following a phase change where the end product is a gas, however, the volume change or expansion can be very large.

The mixing scheme assumes that each component of the compusite mater 1 al (silicate, carbonate, and water) behaves independently of the others in both the loading and the unloading process while in continuous pressure emilibrium. This aerumption is based on an analysis of the timing of the phenomenology of a buried nuclear explosion. When considering thi timing, one realizes that it is not completely an eoujlibrium process. $n 11$ of the energy of the device is released in less than a microsecond.

Calculations have showr, that the rock vaporization stage occurs in about $70 \mathrm{w}^{1 / 3} \mathrm{microseconds}$, where $\mathrm{w}$ is the energy yield in kilctons (4.186 TJ). During this time, an element of composite rock close to the explosion center will have acquired enough $P \Delta V$ energy to be vaporized. Typically, the energy released is distributed to tho surroundi.g material within a few tenths of a second. 17 During thi ${ }^{2}$ time, the shock vaporized mater $i \geq 1$ has expanded to its maximum volume, and the rarefaction from the free surface has returned to a point near the expanded cavity.

Butkovich ${ }^{18}$ has shown that pressure differences of the order of $10^{4} \mathrm{MPa}$ can exist immediately behind a shock front in different types of rock and behind a shock wave of the same velocity in water. Similarly, large differences in temperature and particle velocity would be calculated between the rock components and water. In addition, it was shown that the large pressure differences between the rock matrix and water will equilibrate in time for a shock wave to propagate from region of higher pressure to one of lower nressure. This will occur during a period of time fram a fraction of a 
microseconci to a few microseconds, depending primardy upon how the water inclusions are distributed in the matrix. ${ }^{18}$ since the tame is small compared with a cavity expansion time of 0.1 to 0.3 seconds, it seens reasonalle to assume pressure equilibrium between all the components of the composil:. Huwever, it cannot be demonstrated that temperature equilibrium will he attained in a time which is short compared with full cavity growth time. Estimats: for temperatur a equilibrium, i un 1 rom a few to many seconds dependirig upon the heat transfer mechanism used.

Whr 1 relcuse paths fion composite Hugonlots are reguired, release paths trom solected pacsules on the Hugoniuts for each component are calcuiated and lie componont reinase paths are combined using

$$
\because:=1-z-c) v_{G}+c v_{C}+z v_{W} .
$$

Thr toral veil:mir change upon release is

$$
\because=i v_{r}+i v_{c}+A v_{W}
$$

where " $" \mathrm{G}^{\prime}, \mathrm{V}_{\mathrm{C}}$, and $\mathrm{iV}$ are the volune changes of the three components. Fach relcaser path trom a gjven pressure on the composite Hugoniot is calculated using Eq. (9). That is, taking the p-V release patrs for each component frorr the same hugoniot pressure, the specific volumes for eact component are added according to their weight fractions at the same $P$ tor each point along the paths.

Fjgures $6 a$ and $6 \mathrm{~b}$ show the Hugoniot and release paths for $2.5 \mathrm{~g} / \mathrm{cm}^{3}$ grain density silicate rock and for water, lespectively. Figures 6c, 6d, and 6e show composite Hugoniots and release paths for silicate rock containing, respectively, 10, 20, and $30 \%$ by weight water. Figures $7 a-e$ show the same results in pressure-compression space.

Figures $\mathrm{Ba}, 8 \mathrm{~b}$, and $8 \mathrm{c}$ show the calculated Hugonicts and release paths for a composite rock containing 108 by weight $\mathrm{CaCO}_{3}$ and 0,10 , and 208 by weight water, respectively. Figures $9 a, 9 b$, and $9 c$ show the same results plotted in prtsavie-compression spare.

Fididres 10 and 11 show the effect of air-filled porosity on the release paths. pigures $10 \mathrm{a}-\mathrm{d}$ show the release paths for dry, porous silicate rock with $0,10,21$. , and 308 air-illed porosity, respectively. Note how the compression accounts for the permanent loss of air-filled porosity. 
Figur" Il gives the effect on the release paths of als-filled prousty with carc, wilh Figa. $11 \mathrm{a}, 11 \mathrm{~h}$, and $11 \mathrm{c}$ indicating 0,10 , and 208 artfilled porosity, respectively. Note here a sumilar permanent loss of artfilled prosity. Figures $12 a, 12 b$, and $12 c$ snow the same results plotted in pressure-compression space.

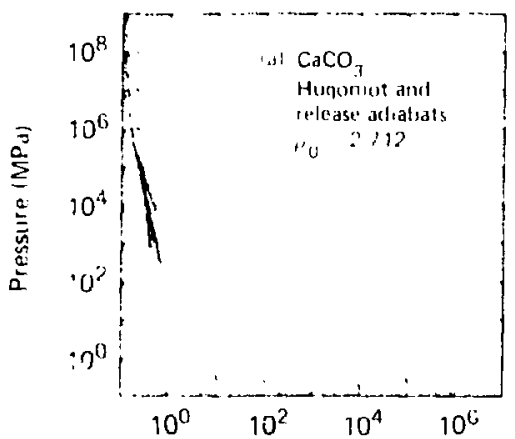

Specific volume $\left(\mathrm{cm}^{3} / \mathrm{g}\right)$

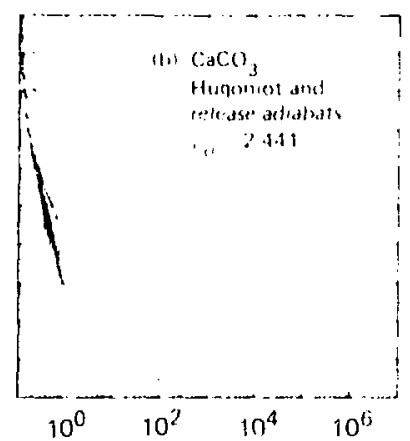

Spesific volume $\left(\mathrm{cm}^{3} / \mathrm{g}\right)$

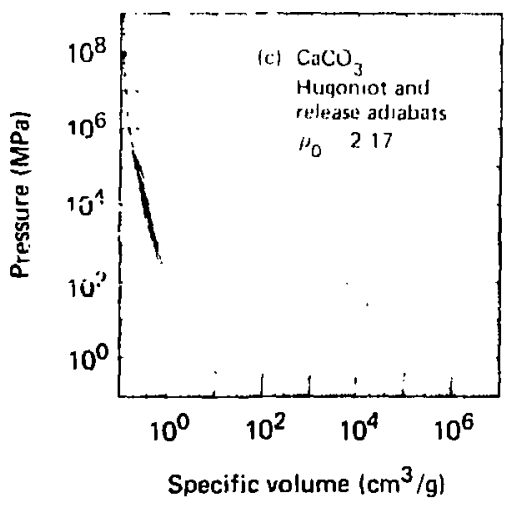

FIG. 11. Release paths for pure $\mathrm{CaCO}_{3}$. 

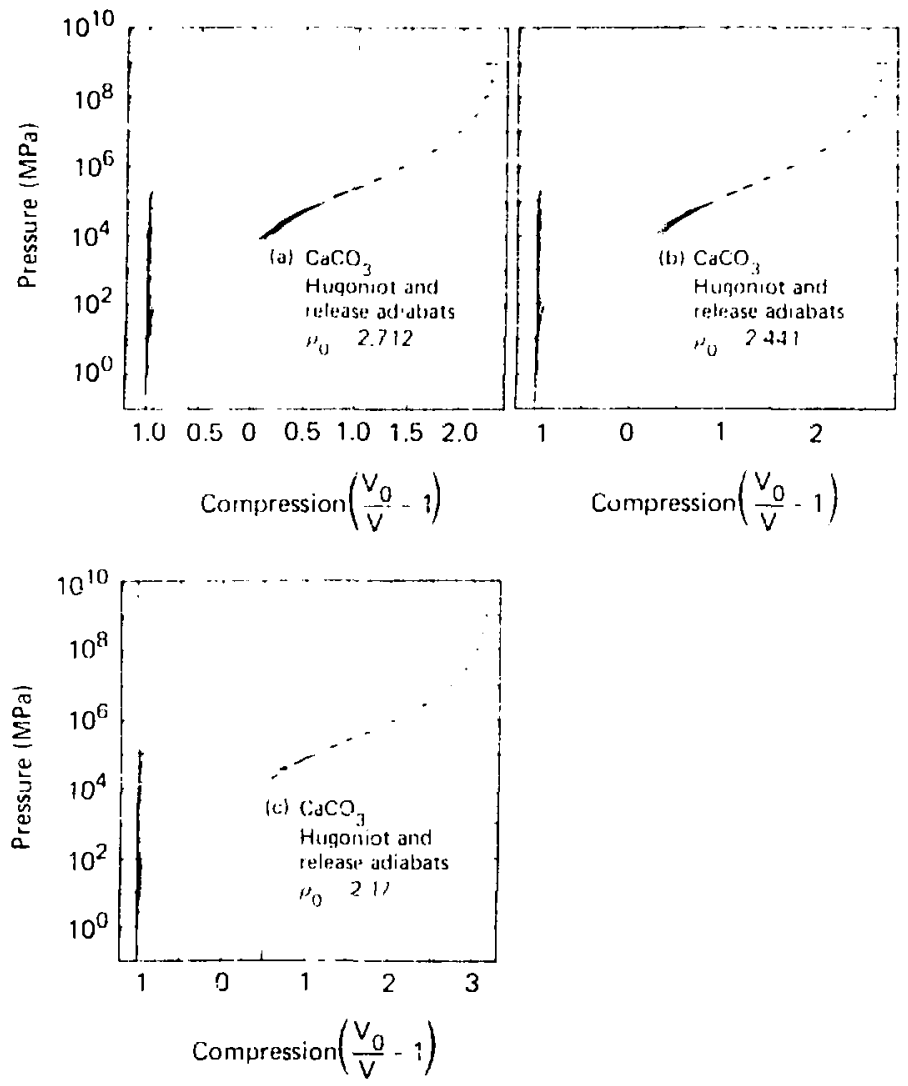

FIG. 12. Release paths for pure $\mathrm{CaCO}_{3}$ in pressure-compression space. 
The LLNL nuclear explosion phenomenology codes isuch as $50 \mathrm{C}$ and TENSOR) require constitutive relations of pressure, density, and energy for the rock surrounding the explosion. Eluation of state inputs for gasenus, liquid, and solid phases are required. Then these are used to caiculate the loading and release paths for each point in the rock affected by the explosion. With pure substances such as silicate, carbonate, or water, equations of state can be deriled from meisurements and theoretical considerationsi for all of the three prases. However, many rocks contain arbitrary mixtures of these subsianzes. Most rocks contain porosity, either partially or fully saturated with water, ani some rocks contain carbonates. The almost infinite variety of mixtures or different weight fractions of the three components makes it impractical to make the measurements which are necessary to define the llugoniot equation of state and inacceptable to calculate the equilibrium gas equation of state for every possible combination. It is much more likely that only simple measurements on a rock sample will be made to determine its bulk density, grain density, water content, and carbonate content.

A technique developed to construct the $\mathrm{P}-\mathrm{V}$ Hugoniat equation of state for porous and non-porous silicate rock that is fully or pirtially saturated with water has been extended to include the carbonate component. The Hugoniut defines the PVE shock states in SOC and TENSOR calculations. If sufficient energy is added to a component of the rock to cause it to vaporize or decompose, release paths from these points are calculated with a gas equation of state. Since the different components require different amounts of energy to vaporize or decompose, each component of the composite rock can be different with any mixture of gases, liquids, and solids, depending upon the peak shock pressure experienced.

With the timing of the explosion phenomenology in mind, the mixing scheme used assumed that the components of the composite rock behave independently of each other while in constant pressure equilibrium in both loading and release, regardless of phase.

Other aspects of the model include the radiation correction to the equilibrium gas equation of state for silicate $\left(\mathrm{SiO}_{2}\right)$, carbonate $\left(\mathrm{CaCO}_{3}\right)$, and water $\left(\mathrm{H}_{2} \mathrm{O}\right)$ and account for the additional energy required to remove porosity that might be present in the silicate and carbonate components of the composite rock. 


\section{ACKNOWLEDGMENT}

The authors wish to acknowledge otis Walton for a critical review of this report and for helpful discussions during the develoment and programming of the model. 


\section{REFERENCES}

1. J. F. Schatz, A One-Dimensiona: Wave Propagation Lrie for Rock Mejia, Lawrence Livermore National Laboratiry, Livermore, CA, UCRL-51689 (1974).

2. D. E. Burton and J. F. Schatz, Rock Modeitig in TEs'SOR74, Lawrence Livermore National Laboratory, Livermore, CA, UCID-16719 (1974).

3. C. A. Rouse, "Innization Equilibrium Equation of State," Astroplys. J. 134,435 (1961).

4. C. A. Rouse, "Icnization Equilibrium Fnuation of State II. Mixtures," Astrophls. J. 134, 599 (1962a).

5. C. A. Rouse, "Ionization Equilibrium Equation of State IIl, Results with Debye-Huckel Correction and Plancks Parition Function," Astrophys. I. $136,636(1962 \mathrm{~b})$.

6. C. A. Rourn, "Ionization Equilibriun Equation of state IV, Dense Planner and Liquid Metals," Astrophys. J. 136, 665 (1962c).

7. C. A. Rouse, "Ionization Equilibrium Equation of State V, Twenty-two Element Mixtures at Stellar Temperatures and Dcnsities," Astrophys. J. 137, 1286 (1963).

8. M. Cowperthwaite and $W$. H. Zwisler, Tiger Compueter Program Documentation, Stanford Research Institute, Palo Altn, CA, Z106 (1974).

9. T. R. Butkovich, A Technique for Genelating Pressure-Volume Relationships and Fracture Ervelopes for Rocks, Lawrence Livermore National Laboratory, Livermore, CA, UCRL-5144] (1973).

10. R. L. Bjork, K. N. Kreyenhagen, and M. H. Wagner, Compressibie Hydrodynamic Analysis of an Underwater Nuclear burst, Shock Hydrodynamics Inc., Report for U.S. Naval Radiological Defense Laboratory No. NROL-TRC-69-6 (1969).

11. F. B. Porzel, Close-in Shock Time of Arr ival Measurements and Hudrodynamic Yjeld, Lawrence Livermore National Laboratory, Livermore, CA, UCRL-5675 (1958).

12. G. H. Higgins, Lawrence Livermore National Laboratory, Livermore, $C A$, private communication.

13. T. R. Butkovich, The Gas Equation of State of Natural Materials, Lawrence Livermore National Laboratory, Livermore, CA, UCRL-14729 (1967).

14. R. W. Tayior, Lawrence Livermore National Laboratory, Livermore, CA, private comunication. 
15. C. E. Chapin and T. R. Butkovich, Radiation Correction of Equation of State Tables Used in the SOC and TENSOR Codes, Lawrence Livermore National Laboratory, Livermore, CA, Internal Memorandum UOPKA 69-34, (1965). Readers outside the Laboratory who desire further irformaticin on Lawrence Livermore National Laboratory internal documents should address their inquiries to the Technical Information Department, Lawrence Livermore National Laboratory, Livermore, CA, 94550.

16. A. Pasternak, E. L. Lee, and D. G. Miller, The Equation of State and Shock Entropy of $\mathrm{CaCO}_{3}$, Lawrence Livermore National Laboratory, Livermore, CA, UCID 17344 (1976).

17. R. W. Terhune, Analysis of Burial Depth Criteria for Containment, Lawrence I ivermore National Laboratory, Livermore, CA, UCRL-52395 (1978).

18. T. R. Butkovich, "Reply to letter," Geophys. Res. 76(35), 10 December 1971. 